Subscriber access provided by King Abdullah University of Science and Technology Library

\title{
Article
}

\section{Supramolecular Isomers of Metal-Organic Frameworks Derived from a Partially Flexible Ligand with Distinct Binding Motifs}

Rasha G. AbdulHalim, Aleksander Shkurenko, Mohamed H Alkordi, and Mohamed Eddaoudi

Cryst. Growth Des., Just Accepted Manuscript • DOI: 10.1021/acs.cgd.5b01307 • Publication Date (Web): 04 Jan 2016

Downloaded from http://pubs.acs.org on January 10, 2016

\section{Just Accepted}

"Just Accepted" manuscripts have been peer-reviewed and accepted for publication. They are posted online prior to technical editing, formatting for publication and author proofing. The American Chemical Society provides "Just Accepted" as a free service to the research community to expedite the dissemination of scientific material as soon as possible after acceptance. "Just Accepted" manuscripts appear in full in PDF format accompanied by an HTML abstract. "Just Accepted" manuscripts have been fully peer reviewed, but should not be considered the official version of record. They are accessible to all readers and citable by the Digital Object Identifier (DOI®). "Just Accepted" is an optional service offered to authors. Therefore, the "Just Accepted" Web site may not include all articles that will be published in the journal. After a manuscript is technically edited and formatted, it will be removed from the "Just Accepted" Web site and published as an ASAP article. Note that technical editing may introduce minor changes to the manuscript text and/or graphics which could affect content, and all legal disclaimers and ethical guidelines that apply to the journal pertain. ACS cannot be held responsible for errors or consequences arising from the use of information contained in these "Just Accepted" manuscripts. 


\title{
Supramolecular Isomers of Metal-Organic Frameworks Derived from a Partially Flexible Ligand with Distinct Binding Motifs
}

\author{
Rasha G. AbdulHalim, Aleksander Shkurenko, Mohamed H. Alkordi, and Mohamed Eddaoudi* \\ Functional Materials Design, Discovery \& Development Research Group (FMD ${ }^{3}$ ), Advanced Membranes \& Porous Materials Center, \\ Division of Physical Sciences and Engineering, King Abdullah University of Science and Technology (KAUST), Thuwal 23955-6900, \\ Kingdom of Saudi Arabia
}

\begin{abstract}
Three novel metal-organic frameworks (MOFs) were isolated upon reacting a heterofunctional ligand 4-(pyrimidin-5-yl)benzoic acid (4,5-pmbc) with mixed valence $\mathrm{Cu}(\mathrm{I}, \mathrm{II})$ under solvothermal conditions. X-ray crystal structural analysis reveals that the first compound is a layered structure composed of one type of inorganic building block, dinuclear paddlewheel $\left[\mathrm{Cu}_{2}\left(\mathrm{O}_{2} \mathrm{C}-\right)_{4}\right]$, which are linked through 4,5-pmbc ligands. The two other supramolecular isomers are composed of the same $\mathrm{Cu}$ (II) dinuclear paddlewheel and a dinuclear $\mathrm{Cu}_{2} \mathrm{I}_{2}$ cluster, which are linked via the 4,5-pmbc linkers to yield two different 3-periodic frameworks with underlying topologies related to lvt and nbo. The observed structural diversity in these structures is due to the distinct coordination modes of the two coordinating moieties (the carboxylate group on the phenyl ring and the N-donor atoms from the pyrimidine moiety).
\end{abstract}

\section{Introduction}

Metal-organic frameworks (MOFs) are a thriving class of functional solid-state materials that have attracted considerable attention due to their modular nature ${ }^{1}$ and accessible pore system for potential use in various key applications, such as catalysis, ${ }^{2}$ luminescence, ${ }^{3}$ gas storage and separation. ${ }^{4}$

In this particular burgeoning class of periodic solids, there has been noticeable efforts and progress toward designing periodic functional structures with desired geometrical attributes and chemical properties for targeted applications. ${ }^{5}$ This route has become reasonably feasible with the implementation of the molecular building block (MBB) approach, where organic and inorganic MBBs with given geometry and directionality (e.g., triangles, squares, etc.) are targeted and pre-selected prior the assembly process. ${ }^{6}$ Markedly, The assembly of preprogrammed MBBs allows the formation of discrete supramolecules of variable geometries, as evidenced by the myriad of metallo-supramolecular polygons, cages and polyhedra. ${ }^{7}$ Perceptively, targeting structures based on the assembly of metallamacrocycles, especially supramolecular hexagons, is of particular interest due to the plausible prospective to mimic biological systems. ${ }^{8-9}$

Nitrogen containing heterocycles have been employed in supramolecular chemistry to target and assemble diverse structures ranging from molecular rings, layered structures to 3-D metal organic frameworks. In particular, pyrimidine based ligands were used successively to construct discrete polygons as well as extended frameworks. ${ }^{10}$ It is worth mentioning that the deliberate synthesis of a particular MOF with a precise and intricate topology starting from simple MBBs is often challenging. Potentially, this could be attributed to the lack of control over the coordination modes of the metal ions and/or the flexibility of the ligand ${ }^{11}$.

Our primary objective was to isolate an extended MOF enclosing hexagonal supramolecular building units. Noticeably, the combi- nation of the two requisite building blocks for the formation of a hexagon, namely a bent ligand $\left(120^{\circ}\right.$ angle) with a linear bridging component, was reported by Stang. ${ }^{12}$ Similarly, discrete metallosupramolecular hexagons based on pyrimidines (e.g. pyrimidine, 2-hydroxypyrimidine, 2,4-dihydroxypyrimidine,

2-aminopyrimdines) have been reported by Navarro et al. ${ }^{13}$

Inspired by the aforementioned discrete assemblies, we opted to use an in-house synthesized pyrimidine-based ligand $\left(\mathrm{H}_{2}-4,5-\right.$ pmbc: 4-(pyrimidyl-5-yl)benzoic acid) and explore its potential in directing the assembly of extended frameworks based on hexagonal supramolecular building units. The 4,5-pmbc is a multifunctional ligand encompassing one carboxylate group and two aromatic N-donors centers, offering several coordination modes as depicted in Scheme 1.

These binding modes include bis-monodentate and bidentate coordination modes for the carboxylate moiety; whereas, the pyrimidyl nitrogen coordinates in a monodentate mode. Scheme 1 (a-c) shows the likely modes of coordination when reacting this ligand with a $\mathrm{Cu}$ (II) metal source prompting the formation of a $\mathrm{Cu}$ (II) paddlewheel (bis-monodentate coordination) at the carboxylate functionality. Scheme 1 (d-f) depicts the relatively less plausible bidentate coordination mode for the $\mathrm{Cu}$ (II) centers.

Scheme 1 ( $b$ and e) depict the case when the nitrogen donor groups on the pyrimidine remain uncoordinated leading preferentially to the formation of discrete 0 -periodic molecular coordination compounds.

In Scheme 1 (c and f), a $120^{\circ}$ angle enclosed by the carboxylate group and the coordinated nitrogen atom in the pyrimidine ring is similar to that observed in isophthalic acid. In this regard, the isophthalate acts as a two connected bent linker bridging the $\left[\mathrm{Cu}_{2}\left(\mathrm{O}_{2} \mathrm{C}-\right)_{4}\right]$ paddlewheel $\mathrm{MBBs}$ to either sustain squares or triangles to form a square grid lattice or a Kagomé layer ${ }^{14}$ respectively. Finally, in Scheme 1 (a and d) the second nitrogen on the 
pyrimidine ring can bridge the clusters and thus potentially promote the formation of a 3-periodic structure based on linked hexagonal polygons.

The combination of MBBs with multidentate ligands has proved to be an efficient pathway for targeting 2-D and 3-D MOFs, including supramolecular isomers. One of the most employed and targeted inorganic MBB is the well-known dinuclear paddlewheel type cluster $\left[\mathrm{M}_{2}\left(\mathrm{O}_{2} \mathrm{C}-\right)_{4}\right]$. This $\mathrm{MBB}$ can be easily targeted through the use of carboxylate based ligands and divalent transition metals $(\mathrm{Cu}, \mathrm{Zn}$, etc.) under mild solvothermal reaction conditions ${ }^{15}$. Examples include edge-transitive layers (square grid or Kagomé) synthesized from dicarboxylate based ligands. Inclusion of bifunctional N-donor based ligands (e.g. 4,4'-bipyridine) in the synthesis allows linking these layers via a "pillaring strategy" by connecting the axial (apical) position of the paddlewheel clusters. ${ }^{16}$

The use of $\mathrm{Cu}(\mathrm{I})$ complexes is particularly attractive because of their promising optical properties and the readily occurrence of various MBBs derived from copper halides $(\mathrm{CuX}) .{ }^{17} \mathrm{CuX}$ reacts readily with nitrogen-donor ligands as a result of the soft-soft bonding preference generating diverse geometries with various $\left[\mathrm{Cu}_{n} \mathrm{I}_{n}\right]$ structural motifs. ${ }^{18}$ These motifs range from $\mathrm{Cu}_{2} \mathrm{I}_{2}$ rhomboid square dimers, ${ }^{19}$ triangular $\mathrm{Cu}_{3} \mathrm{I}_{3}$ clusters, cubane-like or chair like $\left[\mathrm{Cu}_{4} \mathrm{I}_{4}\right]$ tetramers ${ }^{20}$ hexagonal $\mathrm{Cu}_{6} \mathrm{I}_{6}$ clusters ${ }^{21}$, ladderlike or ribbon like $\left[\mathrm{Cu}_{2} \mathrm{I}_{2}\right]_{n}$ chains, ${ }^{22} \operatorname{zigzag}^{23}[\mathrm{CuI}]_{n}$ or $\left[\mathrm{Cu}_{3} \mathrm{I}_{4}\right]_{n}$ chains $^{24}$ and $[\mathrm{CuI}]_{n}$ layers. ${ }^{25}$ Among the various clusters acting as connecting nodes, dimeric and tetrameric units are the most observed clusters. ${ }^{26}$

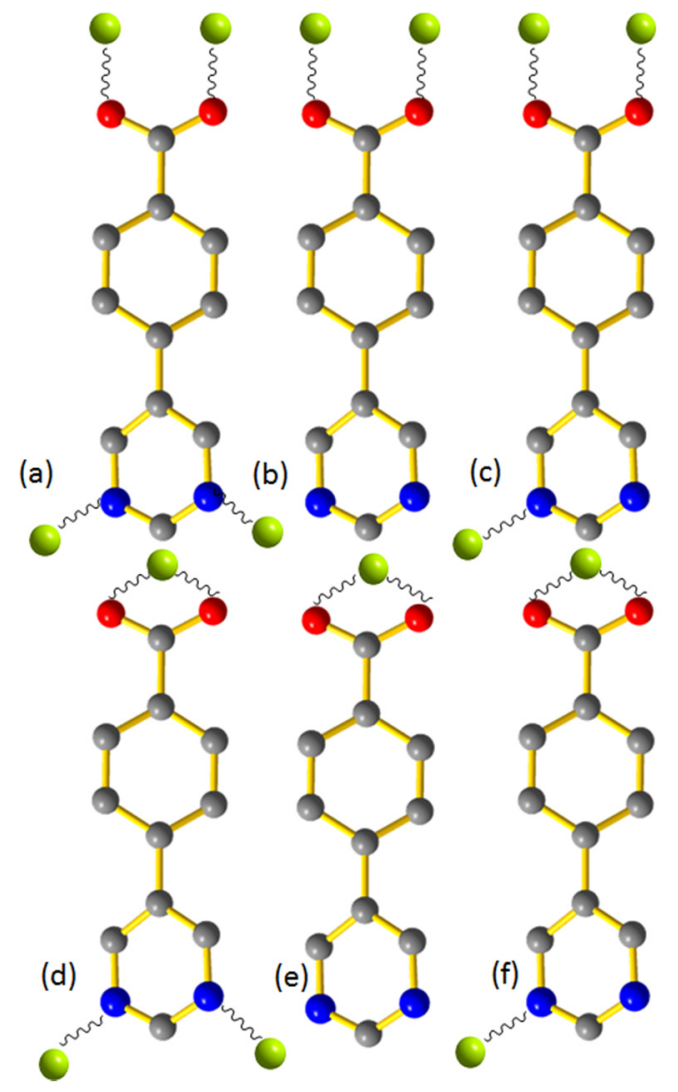

Scheme 1. (a-f) Noted coordination modes of 4,5-pmbc. 1 is composed of (a) and (c), $\mathbf{2}$ and $\mathbf{3}$ of (a) and (b) types of coordination modes. Color code $(\mathrm{C}=$ grey, $\mathrm{O}=$ red, $\mathrm{N}=$ blue; lime balls representing the metal ion)
Our envisioned strategy to construct 3-periodic MOFs encompassing hexagonal supramolecular building units using the heterofunctional ligand $\mathrm{H}_{2}-4,5-$ pmbc in combination with $\mathrm{Cu}(\mathrm{I})$ and $\mathrm{Cu}(\mathrm{II})$, under various solvothermal reaction conditions, had permitted the formation of a layered structure $\mathbf{1}$ and two supramolecular isomers $\mathbf{2}$ and $\mathbf{3}$ with lvt and $\mathbf{n b o}$ underlying topologies, respectively.

\section{Experimental Section}

Preparations: All materials and solvents were used as received from Aldrich Chemical Co. and Fischer Scientific, respectively, without further purifications.

Single-crystal X-ray diffraction data was collected using Bruker X8 PROSPECTOR APEX2 CCD diffractometer $(\mathrm{Cu} \mathrm{K \alpha} \lambda=$ $1.54178 \AA$. Crystallographic data and structural refinements of $\mathbf{1}$, $\mathbf{2}$ and $\mathbf{3}$ are summarized in Table S1. Powder X-ray diffraction (PXRD) measurements were performed on a PANalytical X'Pert PRO MPD X-ray diffractometer at $45 \mathrm{kV}, 40 \mathrm{~mA}$ for $\mathrm{Cu} \mathrm{K} \alpha(\lambda=$ $1.5418 \AA)$. PXRD measurements were performed on DMF washed samples for 1, $\mathbf{2}$ and $\mathbf{3}$, as shown in Figures S4, S5 and S6. High resolution dynamic thermal gravimetric analysis (TGA) were performed under a continuous $\mathrm{N}_{2}$ flow and recorded on a TA Instrument Hi-Res TGAQ500 thermal gravimetric analyzer. TGA experiments were performed on a DMF washed samples for $\mathbf{1 , 2}$ and 3 under $\mathrm{N}_{2}$ and at a heating rate of $5^{\circ} \mathrm{C} \min ^{-1}$, as shown in Figures S1, S2 and S3.

Synthesis of 4-(pyrimidin-5-yl)benzoic acid ( $\left.\mathrm{H}_{2}-4,5-\mathrm{pmbc}\right)$. This compound was prepared according to our previously reported procedure. ${ }^{6}$ In a Schlenk tube under argon atmosphere, a mixture of 5-bromopyrimidine $(8 \mathrm{mmol}, 1.272 \mathrm{~g})$, 4ethoxycarbonylphenylboronic acid $(9 \mathrm{mmol}, 1.746 \mathrm{~g})$, [1,1'-bis(diphenylphosphino) ferrocene] dichloropalladium(II) (0.2 mmol, $0.146 \mathrm{~g}), \quad$ 2-dicyclohexylphosphino-2', $6^{\prime}$ dimethoxybiphenyl $(0.4 \mathrm{mmol}, 0.168 \mathrm{~g})$, finely grinded $\mathrm{K}_{3}\left(\mathrm{PO}_{4}\right)$ $(14 \mathrm{mmol}, 3 \mathrm{~g})$, and 18 -crown-6 ether $(3.7 \mathrm{mmol}, 1 \mathrm{~g})$ in a mixture of degassed THF $(20 \mathrm{~mL})$ and $\mathrm{EtOH}(5 \mathrm{~mL})$ was prepared and reacted at $85^{\circ} \mathrm{C}$ for $24 \mathrm{~h}$. The reaction mixture was then filtered through celite. The residue was subjected to column chromatography (10\% to $40 \%$ EtOAc in hexane) to yield colorless needles (1.7 g, $7.45 \mathrm{mmol}, 93 \%$ yield). Hydrolysis of the ester was accomplished by stirring the solid with 10 equivalents of $\mathrm{NaOH}$ in a mixture of THF/EtOH/water $1: 1: 1 \mathrm{kept}$ at $60^{\circ} \mathrm{C}$ for $24 \mathrm{~h}$, followed by acidification using $1 \mathrm{~N} \mathrm{HCl}$, extraction in EtOAc, drying over $\mathrm{Na}_{2} \mathrm{SO}_{4}$ and stand for crystallization (white solid, $80 \%$ yield). NMR data match those reported earlier ${ }^{27}{ }^{13} \mathrm{C}$ NMR (DMSO-d6, 150MHz): $\delta=155.0,154.9,132.4,132.1$, 130.0, 129.8, 127.2, 127.0. 1H NMR (DMSO-d6, 600MHz): $\delta=$ $9.20(\mathrm{~s}, 1 \mathrm{H}), 9.19(\mathrm{~s}, 1 \mathrm{H}), 8.06(\mathrm{~d}, J=8.4,2 \mathrm{H}), 7.91(\mathrm{~d}, J=7.8$, 2H) ppm.

Synthesis of $\left[\mathrm{Cu}_{2}\left(\mathrm{C}_{11} \mathrm{H}_{7} \mathrm{~N}_{2} \mathrm{O}_{2}\right)_{4}\right] \cdot\left(\mathrm{CH}_{3} \mathrm{CN}\right)_{2}$ (1)

$\mathrm{Cu}\left(\mathrm{NO}_{3}\right)_{2} \cdot 2.5 \mathrm{H}_{2} \mathrm{O} \quad(5.8 \mathrm{mg}, \quad 0.025 \mathrm{mmol})$ and $\mathrm{H}_{2}-4,5-\mathrm{pmbc}$ $(10 \mathrm{mg}, \quad 0.05 \mathrm{mmol})$ were added to a $3 \mathrm{~mL}$ solution of $\mathrm{N}, \mathrm{N}^{\prime}$-dimethylformamide (DMF) and $1 \mathrm{~mL}$ acetonitrile $\left(\mathrm{CH}_{3} \mathrm{CN}\right)$ in a $20 \mathrm{~mL}$ scintillation vial, heated at $85^{\circ} \mathrm{C}$ for $48 \mathrm{~h}$, and cooled to room temperature. The as-synthesized blue rod-like crystals are insoluble in water and common organic solvents.

Synthesis of $\left[\left(\mathrm{Cu}_{2} \mathrm{I}_{2}\right) \mathrm{Cu}_{2}\left(\mathrm{C}_{11} \mathrm{H}_{7} \mathrm{~N}_{2} \mathrm{O}_{2}\right)_{4}\right] \cdot(\mathrm{DMF})_{7.4}\left(\mathrm{H}_{2} \mathrm{O}\right)_{4.6}$ (2)

$\mathrm{CuI}(4.76 \mathrm{mg}, 0.025 \mathrm{mmol})$ and $\mathrm{H}_{2}-4,5-\mathrm{pmbc}(10 \mathrm{mg}, 0.05 \mathrm{mmol})$ were added to a $3 \mathrm{~mL}$ solution of $\mathrm{DMF}$ and $1 \mathrm{~mL}$ of $\mathrm{CH}_{3} \mathrm{CN}$ in a $20 \mathrm{~mL}$ scintillation vial, heated to $85^{\circ} \mathrm{C}$ for $48 \mathrm{~h}$, and cooled to room temperature. The as-synthesized green hexagon-like crystals are insoluble in water and common organic solvents. 


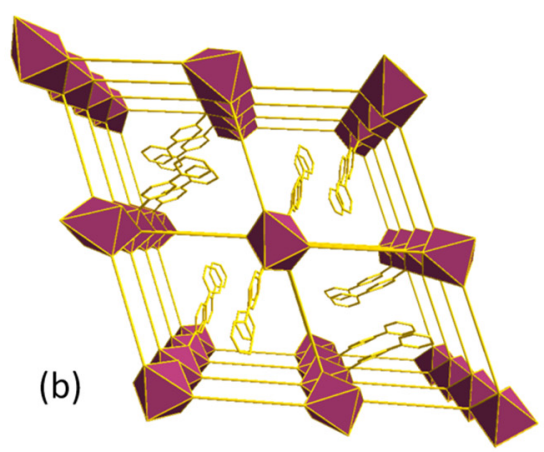

(a)

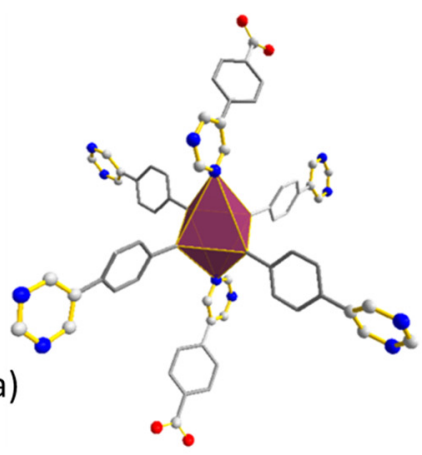

(b)

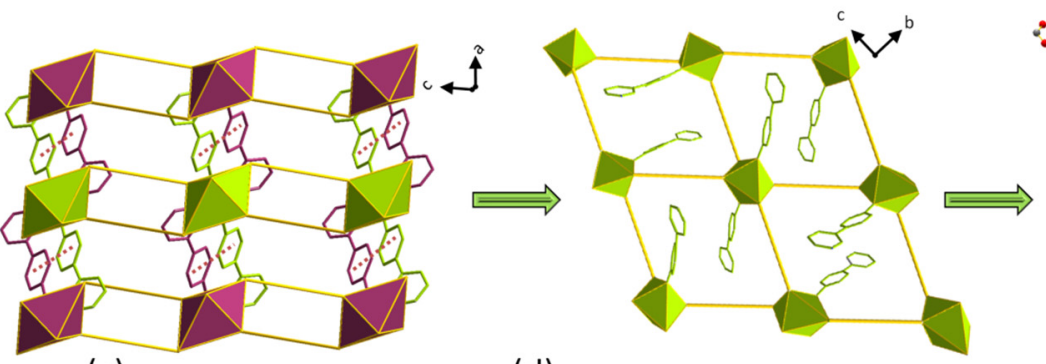

(d)

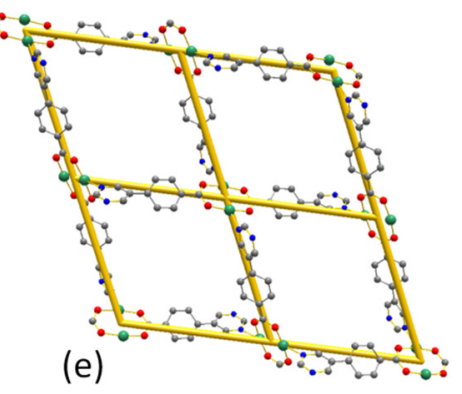

(c)

(e)

Figure 1. Crystal Structure of 1: (a) octahedral coordination environment around the paddlewheel; (b) polyhedral representation of 1 revealing the intercalation of terminal ligands into the channels; (c) the 2-D layers locked through $\pi$ - $\pi$ interactions (illustrated by the dotted lines); (d) highlights one layer; (e) schematic representation of sql topology. Color code ( $\mathrm{C}=$ grey, $\mathrm{O}=$ red, $\mathrm{N}=$ blue).

Synthesis of $\left[\left(\mathrm{Cu}_{2} \mathrm{I}_{2}\right) \mathrm{Cu}_{2}\left(\mathrm{C}_{11} \mathrm{H}_{7} \mathrm{~N}_{2} \mathrm{O}_{2}\right)_{4}\right] \cdot(\mathrm{NMP})_{6.4}\left(\mathrm{H}_{2} \mathrm{O}\right)_{2.4}(3)$

$\mathrm{CuI}(3 \mathrm{mg}, 0.016 \mathrm{mmol}), \mathrm{Cu}\left(\mathrm{NO}_{3}\right)_{2} \cdot 3 \mathrm{H}_{2} \mathrm{O}(4 \mathrm{mg}, 0.016 \mathrm{mmol})$ and $\mathrm{H}_{2}-4,5-\mathrm{pmbc}(6.4 \mathrm{mg}, 0.032 \mathrm{mmol})$ were added to a $2 \mathrm{~mL}$ solution of N-methyl-2-pyrrolidone (NMP), $2 \mathrm{~mL} \mathrm{CH}_{3} \mathrm{CN}$ and $1 \mathrm{~mL} \mathrm{EtOH}$ in a $20 \mathrm{~mL}$ scintillation vial, heated to $85^{\circ} \mathrm{C}$ for $24 \mathrm{~h}$ and cooled to room temperature. The as-synthesized green crystals are insoluble in water and common organic solvents.

\section{Results and Discussions}

Crystals of 1 were isolated by reacting $\mathrm{H}_{2}-4,5$-pmbc in DMF with $\mathrm{Cu}(\mathrm{II})$ under mild conditions. Single-crystal X-ray diffraction (SCXRD) analysis revealed a layered structure that crystallized in a monoclinic space group $P 2_{1} / c$. The layered structure is constructed from dinuclear copper paddlewheel $\left[\mathrm{Cu}_{2}\left(\mathrm{O}_{2} \mathrm{C}-\right)_{4}\right] \mathrm{MBBs}$, where the equatorial plane contains four carboxylate groups from four independent 4,5-pmbc ligands, and the two apical positions are occupied by nitrogen atoms from the pyrimidyl moieties of two separate ligands (Figure 1).Two free ligands with transcarboxylate groups located in the equatorial plane intercalate into the voids of the square grids of adjacent layers filling the empty space (Figure 1a and $1 \mathrm{~b}$ ). Head-to-tail $\pi-\pi$ interactions are observed between pyrimidine and phenyl groups with a mean centroid-centroid distance of 3.789(3) $\AA$ between adjacent layers.

Topological analysis using TOPOS ${ }^{28}$ corroborates the exclusion of the terminal ligands, regarded as no points of extension, as they are not contributing to the overall resultant network connectivity and net underlying topology. Hence the structure can be reduced to a 4-connected net where the 4-c nodes $\left[\mathrm{Cu}_{2}\left(\mathrm{O}_{2} \mathrm{C}-\right)_{2}(\mathrm{~N}-\right.$ )$_{2}$ ] are linked via a bifunctional bent linker to form a 2-periodic MOF structure with a 4,4-connected sql topology (Figure 1e).

As stated earlier, the ability of the two $\mathrm{N}$-donor groups in the pyrimidine ring to concurrently participate in a metal coordination bonding offers potential to augment the connectivity of the 4,5-pmbc ligand and subsequently promote the prospective formation of a 3-periodic MOF structure. The 4,5-pmbc can be re- garded as a partially flexible ligand, where the carboxylate group and the pyrimidine ring can twist and bend, as shown in Figure 2, which could lead to the formation of supramolecular isomers through conformational diversities. In order to target and isolate these isomers, we slightly changed the reaction conditions; either by replacing $\mathrm{Cu}(\mathrm{II})$ with $\mathrm{Cu}(\mathrm{I})$, knowing that $\mathrm{Cu}(\mathrm{I})$ can be oxidized into $\mathrm{Cu}(\mathrm{II})$, as a mean to control the reaction rate which resulted in $\mathbf{2}$, or by mixing both $\mathrm{Cu}(\mathrm{I})$ and $\mathrm{Cu}(\mathrm{II})$ resulting in $\mathbf{3}$.

A solvothermal reaction between $\mathrm{H}_{2}-4,5-\mathrm{pmbc}$ and $\mathrm{CuI}$ in $\mathrm{DMF}$ yielded 2 in pure phase, featuring the formation of two distinct clusters based on $\mathrm{Cu}(\mathrm{I})$ and $\mathrm{Cu}(\mathrm{II})$. The SCXRD analysis of $\mathbf{2}$ revealed the formation of a 3-periodic MOF that crystallized in a tetragonal space group $I 4_{1} / a$.

The resultant structure encloses two distinct types of copper ions $(\mathrm{Cu}(\mathrm{I})$ and $\mathrm{Cu}(\mathrm{II}))$, one type of iodide anion and two crystallographically independent ligands. The overall structure reveals the formation of two distinct inorganic MBBs with the ligand acting as a bifunctional-multidentate linker. MBB-1 is based on a dinuclear cluster represented by copper iodide rhomboid dimeric units $\left[\mathrm{Cu}_{2} \mathrm{I}_{2}\right]$.

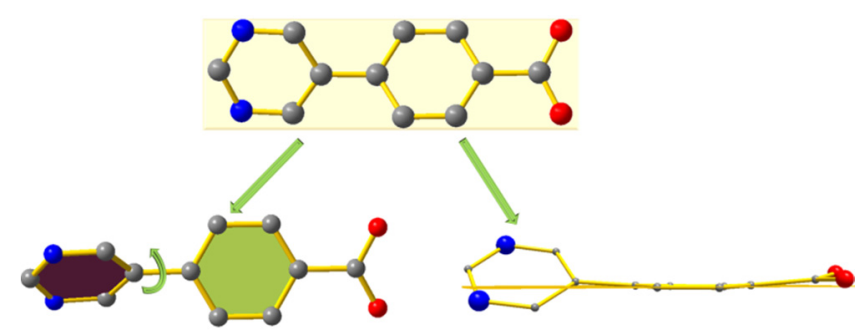

Figure 2. A schematic representation illustrating the twist around the pyrimidine ring, and the bending angle of the carboxylate group. 

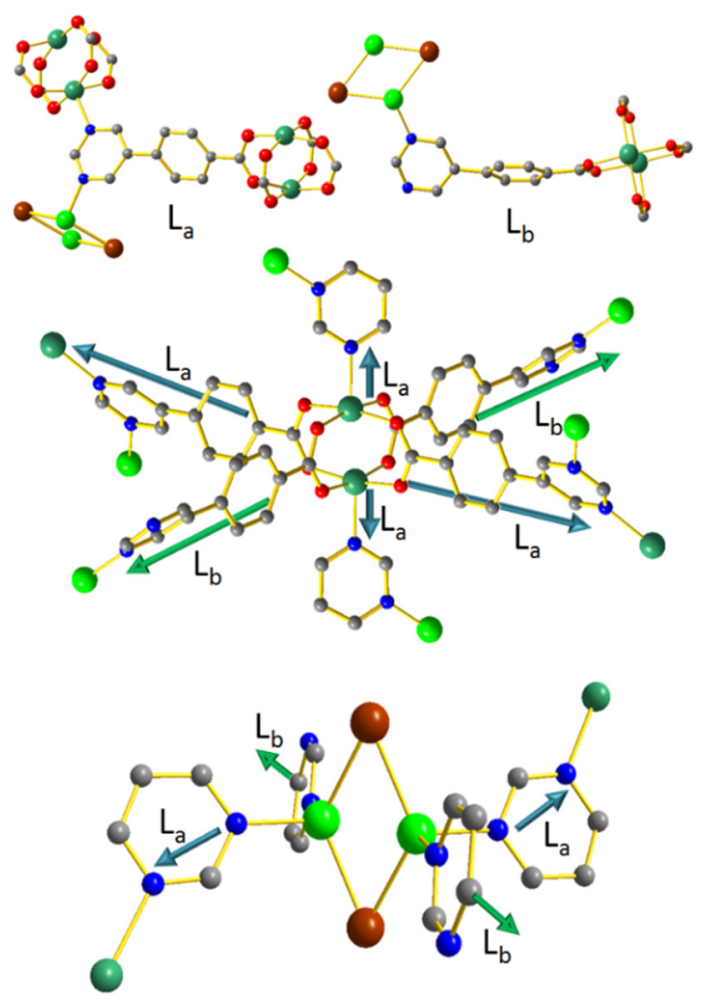

Figure 3. Coordination environments surrounding MBB-1 and MBB-2: 4-connected $\left[\mathrm{Cu}_{2} \mathrm{I}_{2}(\mathrm{~N}-)_{4}\right]$, MBB-1 (to the right). 6connected paddlewheel $\left[\mathrm{Cu}_{2}\left(\mathrm{O}_{2} \mathrm{C}-\right)_{4}(\mathrm{~N}-)_{2}\right]$, MBB-2 (to the left). Color code $(\mathrm{Cu}(\mathrm{I})=$ bright green, $\mathrm{Cu}(\mathrm{II})=$ sea green, $\mathrm{I}=$ brown $)$.

Each $\mathrm{Cu}(\mathrm{I})$ has a tetrahedral coordination geometry with two coordination sites occupied by two nitrogen atoms from two separate ligands and the remaining sites coordinated to two iodide anions. The two $\mathrm{Cu}(\mathrm{I})$ centers are bridged via two iodide anions, balancing the charge, and affording a dinuclear cluster with $\mathrm{Cu}(\mathrm{I}) \cdots \mathrm{Cu}(\mathrm{I})$ distance of $2.537(2) \AA$. MBB-2 is the conventional dinuclear cluster with two $\mathrm{Cu}(\mathrm{II})$ ions, $\left[\mathrm{Cu}_{2}\left(\mathrm{O}_{2} \mathrm{C}-\right)_{4}(\mathrm{~N}-)_{2}\right]$ with $\mathrm{Cu}(\mathrm{II}) \cdots \mathrm{Cu}$ (II) distance of $2.608(2) \AA$. It is to note that there is a significant twist between the phenyl ring and the pyrimidyl ring with dihedral angles of $37.5^{\circ}$ (3) and $44.0^{\circ}$ (3) for $\mathrm{L}_{a}$ and $\mathrm{L}_{b}$ respectively. Each $\mathrm{Cu}$ (II) displays a square pyramidal coordination geometry with four oxygen atoms from four distinct carboxylates and one $\mathrm{N}$-donor from the pyrimidine moiety. The two crystallographic independent ligands show different coordination modes represented by $\mathrm{L}_{\mathrm{a}}$ and $\mathrm{Lb}_{b}$ (Figure 3 ). $\mathrm{L}_{\mathrm{a}}$ acting as a tritopic linker, as shown in Figure 3, where the two $\mathrm{N}$-atoms from the pyrimidine moiety coordinate to two distinct MBBs and the carboxylate group being occluded into the paddlewheel. On the other hand, $\mathrm{Lb}$ with only one of its nitrogen atoms coordinating acts as a bridging linker. Two of the trans- $\mathrm{L}_{\mathrm{b}}$ ligands coordinate through carboxylate groups in a bis-monodentate fashion and contribute to the formation of the dinuclear copper paddlewheel $\left[\mathrm{Cu}_{2}\left(\mathrm{O}_{2} \mathrm{C}-\right)_{4}\right]$ MBB, while the associated pyrimidine moieties coordinate via only one nitrogen and promote the formation of the second inorganic MBB, $\left[\mathrm{Cu}_{2} \mathrm{I}_{2}(\mathrm{~N}-)_{4}\right]$.

As for the tritopic ligand, $\mathrm{L}_{\mathrm{a}}$, apart from the coordination modes observed in $\mathrm{L}_{b}$, links both MBBs to a second MBB-1 through the coordination of the second $\mathrm{N}$-atom on the pyrimidine ring to the apical position of the paddlewheel. Therefore, $\mathrm{L}_{\mathrm{a}}$ spans through two 4-connected MBB-1, $\left[\mathrm{Cu}_{2} \mathrm{I}_{2}(\mathrm{~N}-)_{4}\right]$, and one 6-connected MBB-2, $\left[\mathrm{Cu}_{2}\left(\mathrm{O}_{2} \mathrm{C}-\right)_{4}(\mathrm{~N}-)_{2}\right]$; whereas, $\mathrm{L}_{b}$ spans through one
MBB-1 and one MBB-2. The resulting paddlewheel is surrounded by $4 \mathrm{~L}_{\mathrm{a}}$ ligands and $2 \mathrm{Lb}$ ligands to yield a 6-connected $\mathrm{MBB}$, $\left[\mathrm{Cu}_{2}\left(\mathrm{O}_{2} \mathrm{C}-\right)_{4}(\mathrm{~N}-)_{2}\right]$; whereas, two $\mathrm{L}_{\mathrm{a}}$ and two $\mathrm{Lb}$ support the formation of the 4-connected $\mathrm{MBB},\left[\mathrm{Cu}_{2} \mathrm{I}_{2}(\mathrm{~N}-)_{4}\right]$ (Figure 3). The 3periodic structure in $\mathbf{2}$ is sustained by two dinuclear clusters MBB-1 and MBB-2 that are linked to each other via $\mathrm{L}_{a}$ and $\mathrm{L}_{b}$ to form square-like channels that run along c-axis with a pore diameter of $9 \AA$ (Figure 3 ).

In order to describe the underlying topology of $\mathbf{2}$ and $\mathbf{3}$, it is noteworthy to briefly introduce secondary building units (SBUs) as the geometrical entity representing the points of extension of the molecular building blocks (MBBs). From the viewpoint of an underlying topology, ${ }^{29} \mathbf{2}$ can be simplified as follows. In $\mathbf{2}$, when all coordination sites are considered as points of extension, the connecting nodes becomes as such: MBB-1 coordinating to 6 ligands, forming a 6-c node representing an octahedral building unit, as shown in Figure S7 (a) and (b). The rhomboid dimeric unit $\left[\mathrm{Cu}_{2} \mathrm{I}_{2}(\mathrm{~N}-)_{4}\right]$ can be viewed as a 4-c node (Figure S7 (c) and (d)). $\mathrm{L}_{\mathrm{a}}$ represents a 3-c node, Figure S7 (e) and (f). Hence the overall topology of $\mathbf{2}$ is a new $(3,4,6)$-connected net with a transitivity of [3443], Figure S9.

Compound 3 crystalizes in the hexagonal space group $R-3$. Crystals of $\mathbf{3}$ were obtained under similar reaction conditions to $\mathbf{2}$ upon the addition of a $\mathrm{Cu}(\mathrm{II})$ source. Similar MBBs are observed, MBB-1 containing a paddlewheel forming a 6-c node with an octahedral building unit as all the coordination sites of the dimeric clusters are occupied. In addition, a 4-c rhomboid dimer $\mathrm{Cu}_{2} \mathrm{I}_{2}$ cluster is also isolated, along with both modes of coordination of the 4,5-pmbc, $\mathrm{L}_{\mathrm{a}}$ and $\mathrm{L}_{\mathrm{b}}$. Noticeably, the aromatic rings (phenyl and pyrimidyl) twisted out of plane with dihedral angles of $47.5^{\circ}$ (1) and $46.1^{\circ}$ (1) for $L_{a}$ and $L_{b}$ respectively. The topological analysis of $\mathbf{3}$ has been subjected to similar analysis followed for 2. By accounting for all points of extension, a new $(3,4,6)-c$ net was derived with a transitivity of [3432], Figure S11.

To better understand structures $\mathbf{2}$ and $\mathbf{3}$, we opted to assess the intrinsic roles of each $\mathrm{MBB}$ in the associated structures. Close examination of the respective MBBs connectivity revealed that the rhomboid dimer $\left[\mathrm{Cu}_{2} \mathrm{I}_{2}(\mathrm{~N}-)_{4}\right]$ can be deliberately omitted in the topological analysis and still retain the 3-periodic overall structure. Resultantly, the connectivity of this structure can be simplified by means of the following attributes: $\mathrm{L}_{\mathrm{a}}$ can be regarded as a 2-c node bridging two paddlewheels (Figure S8 (c) and (d) and $\mathrm{Lb}_{b}$ as a terminal ligand upon discounting the $\left[\mathrm{Cu}_{2} \mathrm{I}_{2}(\mathrm{~N}-)_{4}\right]$ (Figure 4, S8 (a)). Subsequently, the resultant connectivity of the paddlewheel differs from the common square $\mathrm{SBU},\left[\mathrm{Cu}_{2}\left(\mathrm{O}_{2} \mathrm{C}-\right)_{4}\right]$, and can be regarded as a lozenge SBU, $\left[\mathrm{Cu}_{2}\left(\mathrm{O}_{2} \mathrm{C}-\right)_{2}(\mathrm{~N}-)_{2}\right]$, when the points of extension are joined together, namely the two carboxylate $\mathrm{C}$-atoms of $\mathrm{L}_{\mathrm{a}}$ and the two pyrimidyl $\mathrm{N}$-atoms (at the apical position) (Figure S8). Noticeably, the simplified structure can be viewed as a 3-periodic network based on 4-c nodes bridged via ditopic linker, resulting in a 4-connected net based on the lvt underlying topology, Figure S10.

Similarly, the topological analysis of structure $\mathbf{3}$ was subjected to identical connectivity simplification as applied to structure $\mathbf{2}$. Noticeably, the exclusion of the rhomboid dimer didn't alter the 3 -periodic nature of the structure. Consequently, the simplified structure of 3 can be regarded as a 3-periodic network based on a 4-c nodes $\mathrm{SBU}$, , $\left[\mathrm{Cu}_{2}\left(\mathrm{O}_{2} \mathrm{C}-\right)_{2}(\mathrm{~N}-)_{2}\right]$, bridged via ditopic $\mathrm{L}_{\mathrm{a}}$ linker, resulting in a 4-connected net based on the nbo underlying topology, Figure S12. 


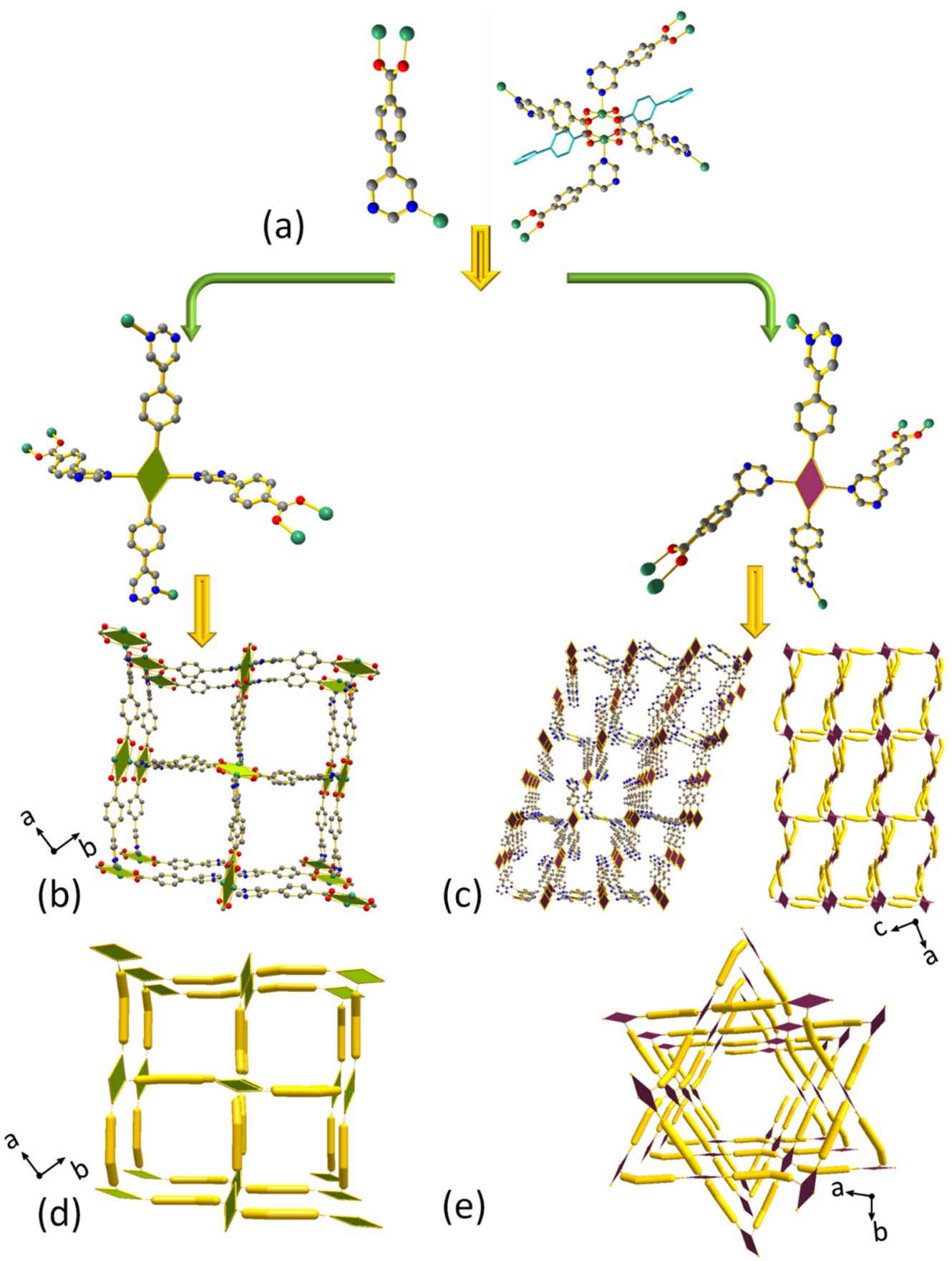

(c)

Figure 4. Topological analysis of 2 and 3; (a) $\mathrm{L}_{\mathrm{a}}$ bridging 4-c paddlewheel and $\mathrm{L}_{\mathrm{b}}$ acting as terminal ligand (highlighted in turquoise); (b) and (c) molecular and schematic illustration of $\mathbf{2}$ and $\mathbf{3}$ as lvt and nbo, respectively; (d) and (e) View along the c-axis showing square and hexagonal channels of $\mathbf{2}$ and $\mathbf{3}$ respectively.

In summary, we here-in report the isolation of a layered structure $\mathbf{1}$ and supramolecular isomers $\mathbf{2}$ and $\mathbf{3}$ with network structural differences. We have shown that the concentration of $\mathrm{Cu}(\mathrm{II})$ in solution plays a role in the isolation of $\mathbf{3}$, which could be driven by the kinetics of the reaction. In addition, the flexibility of 4,5pmbc, allowing both the pyrimidyl group and the carboxylate group to twist and turn, provides additional degree of freedom in which the SBUs can be connected to form supramolecular isomers.

\section{ASSOCIATED CONTENT}

\section{Supporting Information}

PXRD, TGA, structure characterization and crystallographic data. This material is available free of charge via the Internet at http://pubs.acs.org.

\section{AUTHOR INFORMATION}

\section{Corresponding Author}

*Email: mohamed.eddaoudi@kaust.edu.sa 


\section{Notes}

The authors declare no competing financial interest.

\section{ACKNOWLEDGMENT}

This work was supported by the King Abdullah University of Science and Technology (KAUST)

\section{REFERENCES}

1. Furukawa, H.; Ko, N.; Go, Y. B.; Aratani, N.; Choi, S. B.; Choi, E.; Yazaydin, A. O.; Snurr, R. Q.; O'Keeffe, M.; Kim, J.; Yaghi, O. M. Science 2010, 329 (5990), 424-428.

2. Yoon, M.; Srirambalaji, R.; Kim, K. Chem. Rev. 2012, 112 (2), 1196-1231.

3. Cui, Y.; Yue, Y.; Qian, G.; Chen, B. Chem. Rev. 2012, 112 (2), $1126-1162$

4. Eubank, J. F.; Mouttaki, H.; Cairns, A. J.; Belmabkhout, Y.; Wojtas, L.; Luebke, R.; Alkordi, M.; Eddaoudi, M. J. Am. Chem. Soc. 2011, 133 (36), 14204-14207.

5. O'Keeffe, M.; Yaghi, O. M. Chem. Rev. 2012, 112 (2), 675702.

6. Eubank, J. F.; Nouar, F.; Luebke, R.; Cairns, A. J.; Wojtas, L.; Alkordi, M.; Bousquet, T.; Hight, M. R.; Eckert, J.; Embs, J. P.; Georgiev, P. A.; Eddaoudi, M. Angew. Chem. Int. Ed. 2012, 51 (40), 10099-10103.

7. Zheng, Y. R.; Wang, M.; Kobayashi, S.; Stang, P. J. Tetrahedron Lett 2011, 52 (17), 2188-2191.

8. Vicente, J.; Chicote, M. T.; Alvarez-Falcon, M. M.; Jones, P. G. Chem. Commun. 2004, (23), 2658-2659.

9. Wu, N. W.; Chen, L. J.; Wang, C.; Ren, Y. Y.; Li, X.; Xu, L.; Yang, H. B. Chem. Commun. 2014, 50 (32), 4231-4233.

10. Barea, E.; Navarro, J. A. R.; Salas, J. M.; Masciocchi, N.; Galli, S.; Sironi, A. Polyhedron 2003, 22 (22), 3051-3057.

11. Radha Kishan, M.; Tian, J.; Thallapally, P. K.; Fernandez, C. A.; Dalgarno, S. J.; Warren, J. E.; McGrail, B. P.; Atwood, J. L. Chem. Commun. 2010, 46 (4), 538-540.

12. Stang, P. J.; Olenyuk, B. Acc. Chem. Res. 1997, 30 (12), 502518.
13. Navarro, J. A. R.; Barea, E.; Galindo, M. A.; Salas, J. M.; Romero, M. A.; Quirós, M.; Masciocchi, N.; Galli, S.; Sironi, A.; Lippert, B. J. Solid State Chem. 2005, 178 (8), 2436-2451.

14. Moulton, B.; Lu, J.; Hajndl, R.; Hariharan, S.; Zaworotko, M. J. Angew. Chem. Int. Ed. 2002, 41 (15), 2821-2824.

15. Zhang, Z.; Wojtas, L.; Zaworotko, M. J. Cryst. Growth Des. 2011, 11 (5), 1441-1445.

16. Eubank, J. F.; Wojtas, L.; Hight, M. R.; Bousquet, T.; Kravtsov, V.; Eddaoudi, M. J. Am. Chem. Soc. 2011, 133 (44), 17532-17535.

17. Wang, L.-X.; Zhao, L.; Wang, D.-X.; Wang, M.-X. J. Solid State Chem. 2010, 183 (12), 3010-3016.

18. Xu, X.; Bai, X.; Lu, Y.; Wang, E.; Ma, Y. Inorg. Chem. Commun. 2006, 9 (8), 872-876.

19. Sarkar, M.; Biradha, K. Chem. Commun. 2005, (17), 22292231.

20. Hou, Q.; Jia, M.-J.; Zhao, J.-J.; Jin, J.; Yu, J.-H.; Xu, J.-Q. Inorg. Chim. Acta 2012, 384, 287-292.

21. Li, G.; Shi, Z.; Liu, X.; Dai, Z.; Feng, S. Inorg. Chem. 2004, 43 (22), 6884-6886.

22. Yang, X.-J.; Li, H.-X.; Xu, Z.-L.; Li, H.-Y.; Ren, Z.-G.; Lang, J.-P. CrystEngComm 2012, 14 (5), 1641-1652.

23. Zhang, L.; Ren, Z.-G.; Li, H.-X.; Lang, J.-P. CrystEngComm 2011, 13 (5), 1400-1405.

24. Cheng, J.-K.; Yao, Y.-G.; Zhang, J.; Li, Z.-J.; Cai, Z.-W.; Zhang, X.-Y.; Chen, Z.-N.; Chen, Y.-B.; Kang, Y.; Qin, Y.-Y.; Wen, Y.-H. J. Am. Chem. Soc. 2004, 126 (25), 7796-7797.

25. Peng, R.; Wu, T.; Li, D. CrystEngComm 2005, 7 (97), 595598.

26. Prochowicz, D.; Justyniak, I.; Kornowicz, A.; Kaczorowski, T.; Kaszkur, Z.; Lewinski, J. Chemistry 2012, 18 (24), 7367-7371.

27. Henkelis, J. J.; Ronson, T. K.; Harding, L. P.; Hardie, M. J. Chem. Commun. 2011, 47 (23), 6560-6562.

28. Alexandrov, E. V.; Blatov, V. A.; Kochetkov, A. V.; Proserpio, D. M. CrystEngComm 2011, 13 (12), 3947-3958.

29. Delgado-Friedrichs, O.; O'Keeffe, M.; Yaghi, O. M. Phys Chem Chem Phys 2007, 9 (9), 1035-1043. 
For the Table of Content Use Only

\title{
Supramolecular Isomers of Metal-Organic Frameworks Derived from a Partially Flexible Ligand with Distinct Binding Motifs
}

\author{
Rasha G. AbdulHalim, Aleksander Shkurenko, Mohamed H. Alkordi, and Mohamed Eddaoudi*
}

In the present work, three novel MOFs were isolated upon reacting a heterofunctional ligand 4-(pyrimidin-5yl)benzoic acid $(4,5-\mathrm{pmbc})$ with mixed valence $\mathrm{Cu}(\mathrm{I}, \mathrm{II})$ under solvothermal conditions. The two distinct coordinating moieties in the ligand (carboxylate group and the N-donor atoms) prompted the formation of two 3periodic MOFs, supramolecular isomers, with underlying topologies related to lvt and nbo.

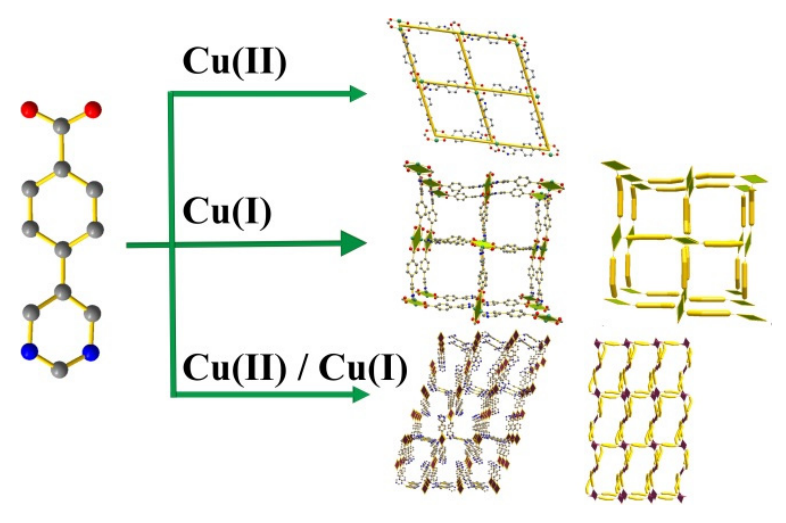

